\title{
Competition and Ideological Diversity: Historical Evidence from US Newspapers
}

\author{
Matthew Gentzkow \\ Chicago Booth and NBER
}

\author{
Jesse M. Shapiro \\ Chicago Booth and NBER
}

February 2014

\author{
Michael Sinkinson \\ The Wharton School
}

\section{Online Appendix}

\section{A Evidence on the Performance of the Model and Solver}

Supplemental appendix tables A.1 and A.2 evaluate the fit of the model to the reduced-form regressions presented in the paper. To evaluate model fit, we repeatedly simulate data from the estimated model and run the same regression on the simulated data that we run on the empirical samples. We average coefficients and standard errors across simulation replications.

Supplemental appendix figure A.1 evaluates the fit of the entry model. The figure shows the relationship between market size and number of papers in the real data and data simulated from the estimated model.

The next six tables evaluate the numerical and econometric behavior of our estimators. In baseline estimates reported in the paper, we constrain all standard deviations and the parameter $\Gamma_{s}$ to be positive. We choose starting values either at zero or at a value (typically one) reflecting the expected order of magnitude of the parameter. We maximize the likelihood using KNITRO's active-set algorithm for unconstrained problems (Byrd et al. 2006). We approximate the integrals in the likelihood equations using sparse grid integration with Gaussian kernel and accuracy 3 (Heiss and Winschel 2008; Skrainka and Judd 2011). The experiments below maintain the same settings except where stated.

Supplemental appendix tables A.3 and A.4 present evidence on the robustness of our model solution to alternative starting values. We repeatedly draw starting values uniformly on a range centered roughly at the main estimated parameters. The tables report the minimum and maximum starting value used for each parameter. In the case of demand estimation, the solver converged from all 20 starts to within $10^{-3}$ of a standard error of our estimated parameters. In the case of supply estimation, in 17 cases the solver converged to within $10^{-3}$ of a standard error of our estimated parameters. In three cases, the solver reported convergence at economically implausible parameter values (extremely high values for variance parameters) with likelihood far below the likelihood at our estimated parameters.

Supplemental appendix tables A.5 and A.6 present evidence on the accuracy of the numerical integrals in our likelihood approximation. In each case, we show estimates of our model using accuracy one below or one above the accuracy used in computing the main estimates. The main estimates are shown in the first column for comparison. 
Supplemental appendix tables A.7 and A.8 report Monte Carlo sampling experiments for our estimator. In each case, we repeatedly simulate data from our model (with estimated parameter values) and re-estimate the model on the simulated data. The difference between the parameters used to simulate the data and those estimated can be taken as an estimate of the finite-sample bias of the estimator. The standard deviation of estimated parameters across replications is a parametric bootstrap standard error, which can be compared to asymptotic standard errors to evaluate the quality of the asymptotic approximation to the sampling distribution of the parameters.

\section{B Robustness of Descriptive Evidence}

Supplemental appendix table B.1 presents additional evidence on the robustness of our key descriptive demand patterns. Specification (1) shows that the effect of household ideology is present when we control carefully for the configuration of the choice set. Specification (2) shows that the effect of proxies for the choice set survives using county fixed effects to control carefully for household characteristics.

Supplemental appendix table B.2 presents additional evidence on the effect of household ideology and the choice set on circulation. Models are OLS regressions of the $\log$ (circulation) of a newspaper in a given town on interactions between newspaper and town characteristics. All specifications include newspaper and town fixed effects, so models can be interpreted as estimates of homogeneous (IIA) logit models with unobservable newspaper quality and unobservable town-specific outside option quality. The baseline specification includes interactions between newspaper affiliation, the Republican vote share, and the numbers of Republican and Democratic newspapers available in the town. The second specification adds interactions between newspaper affiliation and a rich set of town demographics, as well as interactions between the Republican vote share and two non-political newspaper characteristics. We find that Republican newspapers do relatively better in towns with more Republican voters and fewer Republican newspapers. In the model with controls, we find that Republican papers do relatively better in towns with more Democratic newspapers (though this coefficient is not statistically significant).

Supplemental appendix table B.3 shows our key descriptive demand patterns for towns with belowand above-median population. For both groups of towns we find greater relative demand for Republican news in places with more Republican consumers and fewer competing Republican papers. For towns with above-median population we find that there is greater relative demand for Republican papers in places with more Democratic newspapers; for towns with below-median population this effect is wrong-signed and statistically insignificant.

Supplemental appendix table B.4 produces a descriptive analysis of the determinants of newspaper affiliation using our full panel of newspapers, which differs from the sample used in the body of the paper in that it includes newspapers that entered and exited prior to 1924. Column (1) parallels the main descriptive regression in the paper. Quantitatively, the specification in the appendix table shows a similar effect of household ideology and a smaller effect of incumbent affiliation. The latter difference is likely due to the fact that the sample in supplemental appendix table B.4 includes incumbents not present in 1924, who are likely to be smaller, less successful newspapers. Column (2) instruments for our main measure of household ideology with the Republican share of the two-party vote in the presidential election prior to the newspaper's

entry. The fact that coefficients do not change much when we do this corroborates the evidence in Gentzkow et al. (2011) that reverse causality from newspaper affiliation to voting behavior was not a major factor 
during our period of study. Column (3) includes the lag vote share as a control. Conditional on the average Republican vote share, the lag vote share is correlated with newspaper affiliations, but including it in the model has only a small effect on the explanatory power of the model as measured by the $R^{2}$. This finding is consistent with extant evidence that political preferences were highly spatially persistent during the period we study (Glaeser and Ward 2006) and supports our use of the average vote share as the observable proxy for ideology in formal estimation.

\section{Extensions to Descriptive Analysis}

Supplemental appendix figure C.1 shows the effect of consumer ideology and the composition of the choice set on the relative circulation of Republican papers. The relative circulation of Republican papers is greater in towns in which the Republican share of the vote is greater. The relative circulation of Republican papers is lower in towns in which the majority of available newspapers are Republican than in towns in which the majority of available newspapers are Democratic.

Supplemental appendix tables C.1 and C.2 present evidence on the correlation in affiliation choices and circulation patterns across neighboring markets and towns.

Supplemental appendix table C. 3 presents evidence on the effect of ownership on newspapers' affiliation choice. We estimate a random-effects logit model of newspaper affiliation choice, allowing for an ownerspecific random effect and controlling for the Republican share of the two-party vote and the number of Democratic and Republican incumbent newspapers at the time of entry. We restrict attention to newspapers that are part of a multi-newspaper chain. We estimate that the owner-specific random effect accounts for an economically and statistically significant 52 percent of the residual variance.

Supplemental appendix table C.4 presents evidence on whether a given newspaper changes its content over time in response to changes in voter ideology or the competitive landscape. We follow Gentzkow et al. (2011) in measuring the orientation of a newspaper's content by the relative frequency with which the newspaper mentions the Republican presidential ticket. Qualitatively, we find that a newspaper's content becomes more Republican as voters become more Republican, consistent with a simple model of product positioning. The evidence on competitive effects is more mixed: Republicans move to the right when more Democratic papers enter, but Democratic papers do not move to the left as Republicans enter. (If anything, they do the opposite.) None of these findings is statistically significant and the confidence intervals on all parameters are too large to rule out interesting magnitudes.

Supplemental appendix table C.5 presents evidence on changes in newspaper circulation over time in response to changes in consumer ideology and the presence of substitutes. The first column presents a regression of the change in relative circulation of Republican papers on the Republican share of the vote and the change in the number of Republican and Democratic newspapers in the market. This specification is analogous to our descriptive model of town-level circulation, but is estimated on our panel of newspaper markets. For various reasons - measurement error in circulation prior to the introduction of the Audit Bureau of Circulations, idiosyncratic variation in the vote share, and endogenous price responses by newspaperswe do not expect these regressions to be exactly comparable to those we present from our cross-sectional data in the body of the paper. Nevertheless, it is comforting that the qualitative patterns hold up reasonably well in the panel.

The second column of supplemental appendix table C.5 shows results for the simulated analogue of the 
regression in the first column. In each market and year we simulate circulation for each newspaper, incorporating the determination of subscription prices in equilibrium, and taking the number of newspapers of each affiliation as given. We assume that the true ideology $\rho_{m}$ in the market is equal to the contemporaneous Republican vote share, an assumption that almost certainly overstates the true economic content of year-to-year changes in voting patterns. We run the same regression on the simulated data that we run on the observed data in the first column. The effect of changes in the number of competitors is comparable between the two columns, although it is more symmetric in the simulated data than in the observed data. The effect of changes in ideology is larger in the simulated data than in the observed data, an intuitive finding given that our simulations very likely overstate the economic information in year-to-year changes in voting patterns.

Supplemental appendix table C.6 presents evidence on the effect of entries and exits of newspapers on total market circulation, extending the analysis in Gentzkow et al. (2011). Column (1) presents a regression of the change (between adjacent presidential elections) in the log of total circulation in the market on the change in the number of newspapers. Column (2) presents an analogue of column (1) in which we assume circulation does not change for any continuing newspaper. Column (2) can be thought of as capturing the expected value of the coefficient in column (1) if there were no substitution effects. Column (3) allows the

effect of the change in the number of newspapers to accumulate over two presidential election cycles instead of one-say, due to an entering newspaper needing time to build up a subscriber base. Columns (4) and (5) estimate analogues of columns (1) and (3) using data simulated from our model as in supplemental appendix table C.5.

Supplemental appendix table C.7 provides publication information for each of the readership survey reports that we use in our analysis.

Supplemental appendix table C.8 presents evidence from our detailed readership survey data on the relationship between overlap and newspaper affiliation. For each pair of newspapers in the sample, we compute the number of readers that would overlap between the two newspapers in a model in which newspaper demand is completely separable across newspapers, so that the fraction of readers who read any two newspapers is simply the product of the fraction reading each individual newspaper. We then compute the ratio of the observed number of overlapping readers to the number predicted under this benchmark model. We find that this ratio is greater for pairs of newspapers that share an affiliation than for those that do not, although the power of exercise is limited by the very small sample size.

\section{Additional Sensitivity Analysis for Structural Model}

\section{Omitting Unobservables from the Model}

Supplemental appendix table D.1 presents estimates of select parameters from our baseline model and from an alternative model in which we assume there is no unobservable town- or market-level heterogeneity in consumer ideology. Consistent with the findings we report in the paper, we find that key demand parameters are sensitive to excluding unobservable heterogeneity from the model, whereas key supply parameters are less so. 


\section{Allowing for Politically Independent Consumers}

In this section we show how to estimate the fraction of consumers who are politically independent and how to allow for the presence of these consumers in our demand model.

We estimate the fraction independent using variation over time in the presidential vote, and using variation over time in the difference between the presidential and congressional votes. These approaches are familiar from analyses of aggregate election returns (Chapin 1912; Millspaugh 1918; Burnham 1965), though they raise well-known issues of ecological inference (Eldersveld 1952; Cowart 1974).

We assume that in each county $c$ fraction $\delta_{c}$ of consumers are independents and fraction $\left(1-\delta_{c}\right)$ are partisans. Of partisans, fraction $\rho_{c}$ are Republican and fraction $\left(1-\rho_{c}\right)$ are Democrats. Let $\delta=\mathrm{E}\left(\delta_{c}\right)$ be the overall fraction independent in the population.

In each year $y$ there is a presidential election and a congressional election. We observe the fraction $Z_{c y}$ of the (two-party) vote that goes to Republicans in the presidential election and the corresponding fraction $Z_{c y}^{\prime}$ for the congressional election.

Partisans always vote with their party. Only independents change over time or across offices. Let $r_{c y}$ be the fraction of independents that vote Republican in the presidential election in county $c$ at year $y$. Let $r_{c y}^{\prime}$ be the corresponding fraction for the congressional election. Then $Z_{c y}=\left(1-\delta_{c}\right) \rho_{c}+\delta_{c} r_{c y}$ and $Z_{c y}^{\prime}=\left(1-\delta_{c}\right) \rho_{c}+\delta_{c} r_{c y}^{\prime}$.

The key identifying assumptions for our approach will be that the variance of $r_{c y}$ and of $r_{c y}^{\prime}$ and the covariance of $r_{c y}$ and $r_{c y}^{\prime}$ are identical across all counties $c$. With these assumptions we get the following relations which motivate two plug-in estimators for $\delta_{c}$ :

$$
\begin{gathered}
\frac{\delta \sqrt{\operatorname{Var}\left(Z_{c y} \mid c\right)}}{\mathrm{E} \sqrt{\operatorname{Var}\left(Z_{c y} \mid c\right)}}=\delta_{c} \\
\frac{\delta \sqrt{\operatorname{Var}\left(Z_{c y}-Z_{c y}^{\prime} \mid c\right)}}{\mathrm{E} \sqrt{\operatorname{Var}\left(Z_{c y}-Z_{c y}^{\prime} \mid c\right)}}=\delta_{c} .
\end{gathered}
$$

The first equation says that we can measure $\delta_{c}$ in a county $c$ using the variance in the presidential vote share. The second equation says that we can measure $\delta_{c}$ using the variance in the difference between the presidential and congressional vote shares.

We implement these two measures as follows. We estimate $\delta$ as 0.217 , the share of split-ticket votes in Rhode Island in 1906 (Millspaugh 1918). We estimate sample analogues of the remaining statistics using the Republican share of the two-party vote in the presidential and House elections in each county from 1868-1928, obtained from the sources described in the paper.

In supplemental appendix table D.2, we present summary results from estimating our demand and supply model on our full sample, and on subsamples consisting of towns and markets in below- or above-median counties according to the estimated fraction independent. Consistent with intuition, our findings regarding market underprovision of diversity are stronger in the sample with fewer independent consumers and weaker in the sample with more. Our main qualitative conclusions remain unchanged.

In supplemental appendix table D.3, we show the effect of allowing for the presence of politically independent consumers on our estimated demand system. Formally we allow that household $i$ in market $m$ has type $\theta_{\text {im }} \in\{D, I, R\}$ where $I$ represents political independence. An independent household's mean 
utility for a single newspaper does not depend on the newspaper's affiliation:

$$
u_{m}^{I}(B)=\sum_{j \in B}\left(\frac{\bar{\beta}+\underline{\beta}}{2}-\alpha p_{j m}\right)-g_{s}(B) \Gamma_{s}-g_{d}(B) \Gamma_{d} .
$$

We assume that in each market and town there is an exogenous fraction of independent households. All parameters of demand are assumed to be the same for both independent and partisan households.

The first column of the table repeats our demand estimates for our baseline model. The second and third columns present estimates from models that allow for the presence of politically independent households, measured as described above. Allowing for politically independent households leads us to estimate a larger gap between $\bar{\beta}$ and $\underline{\beta}$ than in the baseline model. This is intuitive because partisans are now assumed to represent less than the full population, and hence must be correspondingly more partisan in their tastes for news in order to match the empirical facts.

\section{Extension to Multiple Dimensions of Differentiation}

In this section, we assess the sensitivity of our findings to the presence of unmodeled dimensions of horizontal differentiation. We simulate data from a model in which newspapers choose two horizontal characteristics-political affiliation and time of publication-and we estimate our baseline supply model (with affiliation choice only) on the simulated data to evaluate how well the restricted model's counterfactual simulations approximate those in the data generating model.

Define the "Morning Evening" (ME) model as follows. Denote a newspaper's political affiliation by $\tau_{j m} \in\{R, D\}$ and its time of publication by $\tilde{\tau}_{j m} \in\{M, E\}$. Each newspaper thus chooses an attribute $\left(\tau_{j m}, \tilde{\tau}_{j m}\right) \in\{R, D\} \times\{M, E\}$. Household utility for reading a bundle of newspapers $B$ is given by

$$
u_{i m}(B)=\sum_{j \in B}\left(\tilde{\beta} 1_{\tilde{\tau}_{j m}=M}+\underline{\beta} \mathbf{1}_{\theta_{i m} \neq \tau_{j m}}+\bar{\beta} \mathbf{1}_{\theta_{i m}=\tau_{j m}}-\alpha p_{j m}\right)-g_{s}(B) \Gamma_{s}-g_{d}(B) \Gamma_{d}-h(B) \tilde{\Gamma}+\varepsilon_{i m}(B) .
$$

Here we preserve notation from the paper and add the following new elements: the number $h(B)$ of distinct two-newspaper subsets of bundle $B$ such that the two newspapers have the same time of day, the mean utility $\tilde{\beta}$ of a morning paper relative to an evening paper, and the diminishing utility $\tilde{\Gamma}$ from reading multiple papers at the same time of day. As in the baseline model, newspapers choose their types sequentially, subject to an iid type-1 extreme value attribute-specific cost shock $\xi_{j m}\left(\tau_{j m}, \tilde{\tau}_{j m}\right)$.

We simulate data from the supply-side of the ME model. We set all parameters inherited from the baseline model to their estimated values. We set $\tilde{\beta}=-0.04$ and $\tilde{\Gamma}=0.4$, which allows us to roughly match the observed shares of morning-morning, morning-evening, and evening-evening configurations among twonewspaper markets in our data.

We then estimate our baseline supply model on the simulated data, ignoring the choice of morningevening, and fixing demand parameters at the values reported in the paper.

In table D.4 we compare the counterfactual predictions of the ME model to those of the baseline model estimated on data simulated from the ME model. Although the baseline model is misspecified, it makes qualitative predictions similar to those of the data-generating model, though with somewhat different quantitative predictions. 


\section{Out-of-Sample Performance}

Supplemental appendix table D.5 presents evidence on the fit of our model to the empirical means of subscription prices across market configurations. The model predicts that, conditional on the number of newspapers, the affiliations of the newspapers are not strongly related to the mean subscription price. That prediction is consistent with the data. The model also predicts that markets with more newspapers will have higher subscription prices due to more intense advertising competition. That prediction also holds in the observed data, though more weakly than in data simulated from the model.

Supplemental appendix figure D.1 and table D.6 compare features of the US newspaper market as predicted by our model against observed attributes of the US Newspaper Panel introduced in Gentzkow et al. (2011). We use our baseline model to simulate the number of daily papers and the number of markets with diverse papers in 1924 . We simulate 1868 by assuming that the only change in model parameters between 1868 and 1924 is in a decline in marginal cost $M C$ driven entirely by changes in paper and ink prices. To estimate the percentage difference in $M C$ between these two periods, we multiply the 1924 variable cost share of newsprint and ink, estimated to be 26.5 percent from the Inland Press data, by the percentage difference in the real price of newsprint between the two periods, which is 233 percent higher in 1868 compared to 1924, from Gentzkow et al. (2006).

\section{Additional Counterfactual Analysis}

In supplemental appendix table D.7 we show how the differences between the baseline case and the social optimum depend on the maximum number of firms we permit to enter each market. In the first two columns we reproduce results from the body of the paper, which allow as many as 6 firms per market. In the second two columns we allow only a maximum of 3 papers per market. Both cases show that market equilibrium falls well short of the socially optimal total surplus and diversity of readership.

Supplemental appendix table D.8 shows the results of implementing a fixed cost subsidy on welfare and diversity. We base our counterfactual on a real policy: a fixed cost subsidy in Sweden which favors a local market's "second papers" (i.e., papers with lower circulation than the largest paper in the market; see Gustafsson et al. 2009). We model this by assuming that second and subsequent entrants receive a subsidy of $K_{F}$ dollars, though we note that in our model second entrants need not be smaller in circulation. The surplus-maximizing fixed cost subsidy amounts to a payment of $\$ 12,639$ per year to the average second or subsequent entrant, or approximately 15 percent of pre-subsidy revenue. The Swedish fixed cost subsidy also amounts to roughly 15 percent of pre-subsidy revenue (Gustafsson et al. 2009).

Supplemental appendix figure D.2 illustrates in more detail our finding that there are too few diverse markets in equilibrium. The plot shows the number of diverse markets in our baseline simulations and in simulations from a counterfactual in which the social planner chooses all endogenous post-entry variables, as a function of the size of the partisan majority in the market. The gap between the baseline model and the social-planner benchmark is greatest in markets with similar numbers of $R$ and $D$ consumers. In more

partisan markets, diversity is less common, and the gap between the baseline model and the social-planner benchmark is small. 


\section{Additional Sensitivity Analysis for Policy Experiments}

Supplemental appendix table D.9 presents sensitivity analysis for the marginal cost subsidy and joint ownership policy experiments, following the set of specifications presented in the robustness appendix of the paper. For all specifications we hold the marginal cost subsidy equal to its value in the baseline specification.

\section{E Ideological Diversity of News Media in a Model of Voting}

In this section we specify a model of voting in which voter welfare improves when the news media are ideologically diverse, but the ideological configuration of the news market does not affect expected partisan vote shares.

Let $\omega \in\{D, R\}$ be a binary state of the world with $\operatorname{Pr}(\omega=R)=\frac{1}{2}$. There is a unit mass of voters $i$ each of whom must make a binary choice $v_{i} \in\{D, R\}$ under imperfect information about the state $\omega$. Voter $i$ 's utility from vote $v$ is

$$
u_{i}(v)=\left(2 \mathbf{1}_{v=R}-1\right) \theta_{i}+\mathbf{1}_{v=\omega}
$$

where 1 is the indicator function and $\theta_{i} \sim \operatorname{Unif}\left[-\frac{1}{2}, \frac{1}{2}\right]$ is a preference parameter. The voter has both intrinsic ideology and a preference for voting for the "right" party.

There is an exogenous and known market configuration with 0 , 1 , or 2 newspapers. Each newspaper $j$ has a binary type $\tau_{j} \in\{D, R\}$. Newspapers receive a common signal $s$ whose distribution depends on $\omega$. Each newspaper then makes a report $r_{j}$ that depends on the signal $s$ and the type $\tau_{j}$. Let $\tau \in\{\emptyset, D, R, D R, D D, R R\}$ denote the configuration of the market and let $r$ denote the set of all reports.

Reporting strategies are as follows. With probability $\frac{1}{2}, s=\omega$ and $r_{j}=s \forall j$. With probability $\frac{1}{2}, s=0$ and $r_{j}=\tau_{j} \forall j$. We can think of this as corresponding to a signal structure in which sometimes there is very clear evidence in favor of one side or the other, in which case newspapers are bound to report it, but sometimes the evidence is ambiguous, in which case newspapers may exercise discretion.

Suppose that all voters see the reports $r$ of all newspapers. Then it is easy to verify that the fraction of voters who vote for party $R$ is equal to $\operatorname{Pr}(\omega=R \mid r)$. Moreover, by the law of iterated expectations, $\mathrm{E}(\operatorname{Pr}(\omega=R \mid r))=\frac{1}{2}$ regardless of the number or types of the newspapers $\tau$.

Let $U(\tau)$ denote the average voter's expected utility as a function of the market configuration $\tau$. It is straightforward to verify that $U(R D)>U(R R)=U(D D)=U(R)=U(D)>U(\emptyset)$. Having one newspaper is superior to having no newspaper, but because reporting strategies differ only by type, having two newspapers of the same type is equivalent to having one, and having two newspapers of different types is better than having only one newspaper.

In fact we can go further: configuration $R D$ is preferred by all voters to any particular one-type configuration, strictly so for a positive mass of voters, and any particular one-type configuration is preferred by all voters to no newspaper, again strictly for a positive mass of voters.

It is also easy to show that voters with $\theta_{i}>0$ prefer $\tau=R$ in expectation to $\tau=D$, whereas voters with $\theta_{i}<0$ prefer $\tau=D$ to $\tau=R$, and voters with $\theta_{i} \in\left\{-\frac{1}{2}, 0, \frac{1}{2}\right\}$ are indifferent. That is, voters in this model exhibit a preference for newspapers whose "bias" conforms to their own ideology. The reason is intuitive: voters with high $\theta_{i}$ will only vote for party $D$ if there is very strong evidence that $\omega=D$, which arrives only if $r_{j}=D$ and $\tau_{j}=R$.

Finally, to show how these results generalize, consider a more abstract setting with a state of the world 
and a population of voters who make a decision. Voters' payoffs depend on their decisions and on the state of the world (payoff functions may differ for different voters). Before making a decision every voter sees the reports of all newspapers. Newspapers base their reports on a common signal whose distribution is a function of the true state. There are two types of newspapers, and reporting strategies may differ across but not within newspaper types. The Republican vote share is some function of voters' decisions that is linear in the posterior mean of the state of the world. For technical ease, suppose that the state space, signal space, reporting space, and voter action space are all finite.

It is easy to see that the model outlined above is a special case of this more abstract model. It is also easy to show in general that (i) all voters at least weakly prefer $R D$ to $R$ or $D$, (ii) all voters regard $R R$ as welfareequivalent to $R$ and $D D$ as welfare-equivalent to $D$, and (iii) the Republican vote share is independent of the market configuration.

\section{References}

Byrd, Richard H., Jorge Nocedal and Richard A. Waltz. 2006. KNITRO: An integrated package for nonlinear optimization. In G. di Pillo and M. Roma, eds., Large-Scale Nonlinear Optimization. New York: Springer-Verlag.

Chapin, Stuart F. 1912. The variability of the popular vote at presidential elections. American Journal of Sociology 18(2): 222-240.

Cowart, Andrew T. 1974. A cautionary note on aggregate indicators of split ticket voting. Political Methodology 1(1): 109-130.

Eldersveld, Samuel J. 1952. The independent vote: measurement, characteristics, and implications for party strategy. The American Political Science Review 46(3): 732-753.

Glaeser, Edward L. and Bryce A. Ward. 2006. Myths and realities of American political geography. Journal of Economic Perspectives 20(2): 119-144.

Gustafsson, Karl Erik, Henrik Örnebring, and David A. L. Levy. 2009. Press subsidies and local news: The Swedish case. Reuters Institute for the Study of Journalism Working Paper. 
Supplemental Appendix Table A.1: Fit of demand model

Dependent variable: Average $\log$ (circulation) of R papers - Average $\log$ (circulation) of D papers

\begin{tabular}{lcc}
\hline & $(\mathrm{obs})$ & $(\mathrm{sim})$ \\
\hline Republican vote share & 0.9510 & 1.2264 \\
& $(0.1980)$ & $(0.1556)$ \\
Number of Republican papers & -0.0360 & -0.0370 \\
& $(0.0136)$ & $(0.0038)$ \\
Number of Democratic papers & 0.0174 & 0.0361 \\
& $(0.0154)$ & $(0.0034)$ \\
\hline$R^{2}$ & 0.0127 & 0.0220 \\
Number of counties & 1219 & 1580 \\
Number of observations & 4294 & 4016 \\
\hline
\end{tabular}

Notes: Both columns show results from OLS estimates.

Results in the first column are from the demand estimation sample. Results in the second column are averaged over 5 simulations from our estimated model. Republican vote share is the average Republican share of the two-party vote in presidential elections from 1868-1928.

Supplemental Appendix Table A.2: Fit of supply model

Dependent variable: Dummy for newspaper choosing $\mathrm{R}$ affiliation

\begin{tabular}{lcc}
\hline & $(\mathrm{obs})$ & $(\mathrm{sim})$ \\
\hline Republican vote share & 2.3356 & 2.0384 \\
& $(0.0611)$ & $(0.0287)$ \\
Number of Republican papers & -0.1525 & -0.1018 \\
& $(0.0342)$ & $(0.0296)$ \\
Number of Democratic papers & 0.1260 & 0.0425 \\
& $(0.0297)$ & $(0.0227)$ \\
\hline$R^{2}$ & 0.3819 & 0.3838 \\
Number of markets & 950 & 951 \\
Number of newspapers & 1338 & 1402 \\
\hline
\end{tabular}

Notes: Both columns show results from OLS estimates.

Results in the first column are from the supply estimation sample. Results in the second column are averaged over 5 simulations from our estimated model. Republican vote share is the average Republican share of the two-party vote in presidential elections from 1868-1928. 
Supplemental Appendix Table A.3: Sensitivity of demand model estimates to starting values

\begin{tabular}{lcc}
\hline & \multicolumn{2}{c}{ Range of starting values } \\
Parameter & Minimum & Maximum \\
\hline$\alpha$ & 0.170 & 0.248 \\
$\underline{\beta}$ & -1.066 & -0.013 \\
$\bar{\beta}$ & 0.511 & 1.733 \\
$\Gamma_{s}$ & 0.210 & 1.389 \\
$\Gamma_{d}$ & -0.568 & 0.444 \\
$\sigma_{\zeta}$ & 0.277 & 1.798 \\
$\mu_{v}^{\text {town }}$ & -0.802 & 0.784 \\
$\sigma_{v}^{\text {town }}$ & 0.112 & 0.751 \\
$\mu_{\rho}^{0}$ & -1.048 & 0.848 \\
$\mu_{\rho}^{1}$ & 1.209 & 2.910 \\
\hline
\end{tabular}

Notes: The table reports the actual start value ranges of our 20 randomly drawn starting values.

Supplemental Appendix Table A.4: Sensitivity of supply model estimates to starting values

\begin{tabular}{lcc}
\hline & \multicolumn{2}{c}{ Range of starting values } \\
Parameter & Minimum & Maximum \\
\hline$a_{l}$ & 1.811 & 11.307 \\
$\sigma_{\xi}$ & 0.259 & 4.776 \\
$\mu_{v}^{m k t}$ & -1.938 & 1.837 \\
$\sigma_{v}^{m k t}$ & 0.010 & 23.957 \\
$\mu_{\kappa}^{0}$ & -0.720 & 9.486 \\
$\mu_{\kappa}^{1}$ & -1.761 & 1.848 \\
$\sigma_{\kappa}$ & 0.138 & 6.055 \\
\hline
\end{tabular}

Notes: The table reports the actual start value ranges of our 20 randomly drawn starting values. 
Supplemental Appendix Table A.5: Sensitivity of demand model estimates to accuracy of numerical integral

\begin{tabular}{lccc}
\hline Parameter & $\begin{array}{c}\text { Baseline } \\
\text { accuracy }\end{array}$ & $\begin{array}{c}\text { Lower } \\
\text { accuracy }\end{array}$ & $\begin{array}{c}\text { Higher } \\
\text { accuracy }\end{array}$ \\
\hline$\alpha$ & 0.1798 & 0.1791 & 0.1797 \\
$\underline{\beta}$ & -0.2906 & -0.2761 & -0.2877 \\
$\bar{\beta}$ & 0.8137 & 0.7974 & 0.8104 \\
$\Gamma_{s}$ & 0.5645 & 0.5671 & 0.5654 \\
$\Gamma_{d}$ & 0.3004 & 0.3104 & 0.3025 \\
$\sigma_{\zeta}$ & 0.7017 & 0.7022 & 0.7018 \\
$\mu_{v}^{\text {town }}$ & 0.0466 & 0.0479 & 0.0469 \\
$\sigma_{v}^{\text {town }}$ & 0.2783 & 0.2691 & 0.2763 \\
$\mu_{\rho}^{0}$ & -0.0714 & -0.0760 & -0.0725 \\
$\mu_{\rho}^{1}$ & 1.9952 & 1.9858 & 1.9943 \\
\hline Quadrature accuracy & 3 & 2 & 4 \\
\hline
\end{tabular}

Notes: The first column reports the main estimates from the paper. The second and third columns report estimates using quadrature accuracy one below and one above that used to compute the main estimates, respectively.

Supplemental Appendix Table A.6: Sensitivity of supply model estimates to accuracy of numerical integral

\begin{tabular}{lccc}
\hline Parameter & $\begin{array}{c}\text { Baseline } \\
\text { accuracy }\end{array}$ & $\begin{array}{c}\text { Lower } \\
\text { accuracy }\end{array}$ & $\begin{array}{c}\text { Higher } \\
\text { accuracy }\end{array}$ \\
\hline$a_{l}$ & 7.4447 & 7.4345 & 7.4417 \\
$\sigma_{\xi}$ & 0.2277 & 0.2288 & 0.2279 \\
$\mu_{v}^{m k t}$ & -0.0114 & -0.0113 & -0.0113 \\
$\sigma_{v}^{m k t}$ & 0.1523 & 0.1454 & 0.1505 \\
$\mu_{\kappa}^{0}$ & 8.7354 & 8.7363 & 8.7358 \\
$\mu_{\kappa}^{1}$ & -0.6448 & -0.6449 & -0.6448 \\
$\sigma_{\kappa}$ & 0.3607 & 0.3608 & 0.3607 \\
\hline Quadrature accuracy & 3 & 2 & 4 \\
\hline
\end{tabular}

Notes: The first column reports the main estimates from the paper. The second and third columns report estimates using quadrature accuracy one below and one above that used to compute the main estimates, respectively. 
Supplemental Appendix Table A.7: Monte Carlo experiments for demand model

\begin{tabular}{lcccc}
\hline Parameter & $\begin{array}{c}\text { Baseline } \\
\text { estimate }\end{array}$ & $\begin{array}{c}\text { Average estimate } \\
\text { across simulations }\end{array}$ & $\begin{array}{c}\text { Asymptotic } \\
\text { standard errors }\end{array}$ & $\begin{array}{c}\text { Bootstrap } \\
\text { standard errors }\end{array}$ \\
\hline$\alpha$ & 0.1798 & 0.1799 & 0.0032 & 0.0039 \\
$\underline{\beta}$ & -0.2906 & -0.2869 & 0.0676 & 0.0819 \\
$\bar{\beta}$ & 0.8137 & 0.8102 & 0.0759 & 0.0920 \\
$\Gamma_{s}$ & 0.5645 & 0.5700 & 0.0669 & 0.0595 \\
$\Gamma_{d}$ & 0.3004 & 0.2991 & 0.0469 & 0.0572 \\
$\sigma_{\zeta}$ & 0.7017 & 0.6993 & 0.0077 & 0.0089 \\
$\mu_{v}^{\text {town }}$ & 0.0466 & 0.0571 & 0.0422 & 0.0537 \\
$\sigma_{v}^{\text {town }}$ & 0.2783 & 0.2702 & 0.0135 & 0.0083 \\
$\mu_{\rho}^{0}$ & -0.0714 & -0.0921 & 0.0850 & 0.1134 \\
$\mu_{\rho}^{1}$ & 1.9952 & 1.9927 & 0.0336 & 0.0326 \\
\hline
\end{tabular}

Notes: The table reports the results of Monte Carlo experiments in which we first simulate 20 datasets from our model at the parameter values shown in the first column, then re-estimate our model on each simulated dataset.

Supplemental Appendix Table A.8: Monte Carlo experiments for supply model

\begin{tabular}{lcccc}
\hline Parameter & $\begin{array}{c}\text { Baseline } \\
\text { estimate }\end{array}$ & $\begin{array}{c}\text { Average estimate } \\
\text { across simulations }\end{array}$ & $\begin{array}{c}\text { Asymptotic } \\
\text { standard errors }\end{array}$ & $\begin{array}{c}\text { Bootstrap } \\
\text { standard errors }\end{array}$ \\
\hline$a_{l}$ & 7.4447 & 7.3657 & 1.2626 & 1.2431 \\
$\sigma_{\xi}$ & 0.2277 & 0.2290 & 0.0298 & 0.0139 \\
$\mu_{v}^{m k t}$ & -0.0114 & -0.0081 & 0.0184 & 0.0168 \\
$\sigma_{v}^{m k t}$ & 0.1523 & 0.1470 & 0.0684 & 0.0396 \\
$\mu_{\kappa}^{0}$ & 8.7354 & 8.7225 & 0.4860 & 0.3937 \\
$\mu_{\kappa}^{1}$ & -0.6448 & -0.6435 & 0.0618 & 0.0542 \\
$\sigma_{\kappa}$ & 0.3607 & 0.3582 & 0.0345 & 0.0286 \\
\hline
\end{tabular}

Notes: The table reports the results of Monte Carlo experiments in which we first simulate 20 datasets from our model at the parameter values shown in the first column, then re-estimate our model on each simulated dataset. 
Supplemental Appendix Table B.1: Additional evidence on the demand for partisanship

Dependent variable: Average $\log$ (circulation) of R papers - Average $\log$ (circulation) of D papers

\begin{tabular}{lcc}
\hline & $(1)$ & $(2)$ \\
\hline Republican vote share & 0.9430 & \\
& $(0.2053)$ & \\
Number of Republican papers & & -0.1322 \\
& & $(0.0210)$ \\
Number of Democratic papers & & 0.1148 \\
& & $(0.0273)$ \\
Fixed effects for: & & \\
$\quad$ Choice set configuration & $\mathrm{X}$ & \\
$\quad$ County & & $\mathrm{X}$ \\
\hline$R^{2}$ & 0.0237 & 0.5684 \\
Number of counties & 1219 & 1219 \\
Number of towns & 4294 & 4294 \\
\hline
\end{tabular}

Notes: Data are from the demand estimation sample. The dependent variable is the difference in mean log circulation of Republican and Democrat newspapers. Republican vote share is the average Republican share of the two-party vote in presidential elections from 1868-1928. Fixed effects for choice set configuration are unique fixed effects for each possible combination of (Number of Republican papers, Number of Democratic papers). Standard errors in parentheses are clustered at the county level. 
Supplemental Appendix Table B.2: Additional evidence on the determinants of newspaper demand Dependent variable: $\log ($ circulation $)$

\begin{tabular}{|c|c|c|}
\hline & (1) & $(2)$ \\
\hline \multicolumn{3}{|l|}{ Republican newspaper $\times$} \\
\hline \multirow[t]{2}{*}{ Republican vote share } & 0.9089 & 0.9618 \\
\hline & $(0.2614)$ & $(0.2677)$ \\
\hline \multirow[t]{2}{*}{ Number of Republican papers } & -0.0429 & -0.0438 \\
\hline & $(0.0156)$ & $(0.0154)$ \\
\hline \multirow[t]{2}{*}{ Number of Democratic papers } & -0.0010 & 0.0070 \\
\hline & $(0.0231)$ & $(0.0215)$ \\
\hline \multirow[t]{2}{*}{$\%$ White } & & 1.1133 \\
\hline & & $(0.4321)$ \\
\hline \multirow[t]{2}{*}{ \%Illiterate } & & -0.3655 \\
\hline & & $(1.3745)$ \\
\hline \multirow[t]{2}{*}{$\% 21+$ years } & & -0.7937 \\
\hline & & $(0.6742)$ \\
\hline \multirow[t]{2}{*}{$\%$ Male } & & -0.7309 \\
\hline & & $(1.4314)$ \\
\hline \multirow[t]{2}{*}{$\%$ In $2.5 \mathrm{k}+$ pop city } & & 0.3576 \\
\hline & & $(0.1105)$ \\
\hline \multirow[t]{2}{*}{$\%$ Foreign born } & & -0.8312 \\
\hline & & $(0.6132)$ \\
\hline \multirow[t]{2}{*}{$\%$ Employed } & & -1.0979 \\
\hline & & $(0.6624)$ \\
\hline \multirow[t]{2}{*}{ \%Church members } & & 0.3329 \\
\hline & & $(0.1924)$ \\
\hline \multicolumn{3}{|l|}{ Republican vote share $\times$} \\
\hline \multirow[t]{2}{*}{ Morning paper } & & 0.0777 \\
\hline & & $(0.2304)$ \\
\hline \multirow[t]{2}{*}{ Long paper (16+ pages) } & & -0.1337 \\
\hline & & $(0.2760)$ \\
\hline Newspaper fixed effects? & $\mathrm{X}$ & $\mathrm{X}$ \\
\hline Town fixed effects? & $\mathrm{X}$ & $\mathrm{X}$ \\
\hline$R^{2}$ & 0.6717 & 0.6732 \\
\hline Number of counties & 2742 & 2706 \\
\hline Number of newspaper-towns & 30740 & 30655 \\
\hline
\end{tabular}

Notes: The unit of observation is the newspaper-town. Independent variables are characteristics of counties (interacted with a dummy for whether the newspaper has a Republican affiliation) and characteristics of newspapers (interacted with town-level Republican vote share). Republican vote share is the average Republican share of the two-party vote in presidential elections from 1868-1928. Fraction white, illiterate, age $21+$, male, and living in cities of $2.5 \mathrm{k}+$ in county are from the 1920 Census. Fraction foreign-born and employed in county are from the 1940 Census. Fraction church members is from the 1950 Census.

Newspaper publication time (morning vs. evening) is measured in 1924. "Long" papers are characterized as those which have at least 16 pages (the median) as of the most recent year of measurement prior to 1924 . Standard errors in parentheses are clustered by county. 
Supplemental Appendix Table B.3: Demand for partisanship by town population

Dependent variable: Average $\log$ (circulation) of R papers - Average $\log$ (circulation) of D papers

\begin{tabular}{lcc}
\hline & \multicolumn{2}{c}{ Town population: } \\
& $\begin{array}{c}\text { Below } \\
\text { median }\end{array}$ & $\begin{array}{c}\text { Above } \\
\text { median }\end{array}$ \\
\hline Republican vote share & 0.6212 & 1.2242 \\
& $(0.2203)$ & $(0.2678)$ \\
Number of Republican papers & -0.0491 & -0.0314 \\
& $(0.0190)$ & $(0.0171)$ \\
Number of Democratic papers & -0.0209 & 0.0281 \\
& $(0.0221)$ & $(0.0193)$ \\
\hline$R^{2}$ & 0.0092 & 0.0185 \\
Number of counties & 863 & 911 \\
Number of towns & 2147 & 2147 \\
\hline
\end{tabular}

Notes: Data are from the demand estimation sample described in the paper. The dependent variable is the difference in mean log circulation of Republican and Democrat newspapers. Republican vote share is the average Republican share of the two-party vote in the county in presidential elections from 1868-1928. Standard errors in parentheses are clustered at the county level. 
Supplemental Appendix Table B.4: Panel evidence on determinants of newspaper affiliation

Dependent variable: Dummy for newspaper choosing Republican affiliation

\begin{tabular}{lccc}
\hline & $(1)$ & $(2)$ & $(3)$ \\
\hline Republican vote share & 2.1344 & 2.2346 & 1.9400 \\
& $(0.0568)$ & $(0.0711)$ & $(0.1028)$ \\
Number of Republican incumbents & -0.0771 & -0.0823 & -0.0767 \\
& $(0.0129)$ & $(0.0134)$ & $(0.0128)$ \\
Number of Democratic incumbents & 0.0634 & 0.0698 & 0.0635 \\
& $(0.0125)$ & $(0.0129)$ & $(0.0125)$ \\
Lag Republican vote share & & & 0.2048 \\
& & & $(0.0870)$ \\
Instrument with lag vote share? & & $\mathrm{X}$ & \\
\hline$R^{2}$ & 0.2865 & 0.2859 & 0.2876 \\
Number of markets & 1338 & 1338 & 1338 \\
Number of newspapers & 3179 & 3179 & 3179 \\
\hline
\end{tabular}

Notes: Data are from US Newspaper Panel from 1872-1928. The unit of analysis is the newspaper.

Republican vote share is the average Republican share of the two-party vote in presidential elections from 1868-1928. Lag Republican vote share is the Republican share of the two-party vote in the presidential election prior to the entry of the newspaper. The sample excludes newspapers for which data on Republican share of the two-party vote in the election prior to entry is unavailable. Model (1) is an OLS regression. Model (2) is a 2SLS regression in which the lag vote share is used as an instrument for the Republican vote share. All models include fixed effects for the year of entry (the first presidential election year in which the newspaper is present in the panel). The number of Republican/Democratic incumbents is the number of newspapers of each affiliation present in the year of entry. Standard errors in parentheses are clustered at the market level. 
Supplemental Appendix Table C.1: Affiliation choices in own and neighboring markets

\begin{tabular}{lcc}
\multicolumn{2}{c}{ Share of second entrants choosing R affiliation } \\
\hline & \multicolumn{2}{c}{ Second entrant in: } \\
& Own market & Neighboring market \\
\hline First entrant's affiliation: & 0.48 & 0.31 \\
Democratic & 0.51 & 0.64 \\
Republican & \multicolumn{3}{c}{269} \\
\hline Number of markets
\end{tabular}

Notes: Data are from the cross-section of daily newspaper markets in 1924 defined in the body of the paper. The table includes all markets with at least two newspapers in which the neighboring market has at least one newspaper.

Supplemental Appendix Table C.2: Circulation patterns in own and neighboring towns

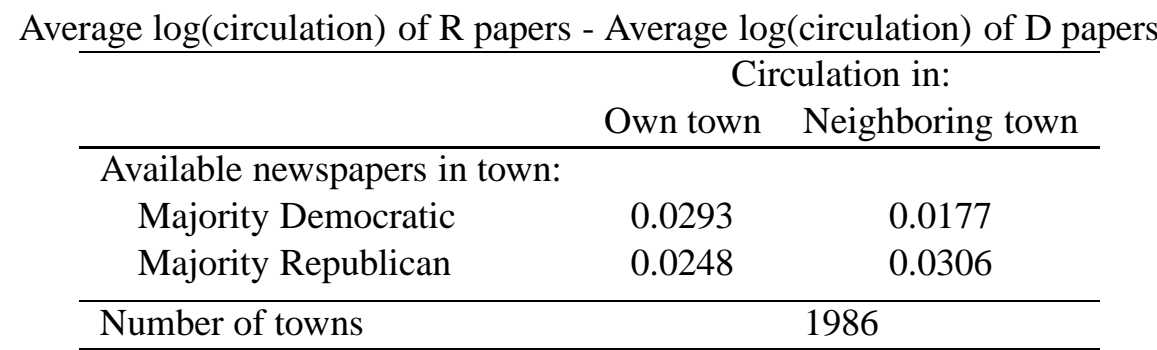

Notes: Data are from the cross-section of news-reading towns in 1924 defined in the body of the paper. The table includes all pairs of towns with at least one newspaper of each affiliation in each town, excluding towns with an equal number of Democratic and Republican newspapers. 
Supplemental Appendix Table C.3: Evidence on the role of ownership in determining affiliation

Dependent variable: Dummy for newspaper choosing R affiliation

\begin{tabular}{lc}
\hline Ownership proportion of total variance & 0.5199 \\
& $(0.2347)$ \\
\hline p-value $\left(H_{0}:\right.$ Ownership proportion of total variance $\left.=0\right)$ & 0.0221 \\
\hline Number of newspapers & 109 \\
Number of owners & 31 \\
\hline
\end{tabular}

Notes: Unit of analysis is the newspaper. Estimates are from a random-effects logit model with a random effect for the newspaper's owner. Estimates are for the sample of newspapers that belong to a multi-newspaper chain as of 1932 . The model includes as covariates the average Republican share of the two-party vote in presidential elections from 1868-1928 and the number of Republican/Democratic incumbents as of the newspaper's entry.

Supplemental Appendix Table C.4: Evidence on changes in a given newspaper's content over time Dependent variable: Change in share of mentions to Republican candidate

\begin{tabular}{lcc}
\hline Newspaper affiliation: & Democratic & Republican \\
\hline Change in & & \\
Republican share of two-party vote & 0.0799 & 0.3282 \\
& $(0.1751)$ & $(0.2170)$ \\
Number of Democratic papers & -0.0152 & 0.0991 \\
& $(0.0615)$ & $(0.0605)$ \\
Number of Republican papers & 0.0565 & -0.0136 \\
& $(0.0876)$ & $(0.0496)$ \\
\hline$R^{2}$ & 0.3737 & 0.4416 \\
Number of newspapers & 37 & 63 \\
Number of newspaper-years & 116 & 226 \\
\hline
\end{tabular}

Notes: Unit of analysis is the newspaper-year. Data are from presidential election years 1868-1928. All models include election-year fixed effects. The dependent variable is the change in the Republican share of mentions of either the Republican or Democratic presidential or vice-presidential candidate. Data were obtained from www.newspaperarchive.com. See Gentzkow, Shapiro, and Sinkinson (2011) for details. Standard errors in parentheses are clustered by newspaper. 
Supplemental Appendix Table C.5: Panel evidence on demand for partisanship

Dependent variable: Change in average $\log ($ circulation) of $\mathrm{R}$ papers - Change in average $\log$ (circulation) of $\mathrm{D}$ papers

\begin{tabular}{lcc}
\hline Data Source: & Observed & Simulated \\
\hline Change in & & \\
Republican share of two-party vote & 0.2003 & \\
(observed) & $(0.0785)$ & \\
True share Republican & & 1.2345 \\
$(\rho)$ & & $(0.0054)$ \\
Number of Republican papers & -0.0339 & -0.0381 \\
& $(0.0175)$ & $(0.0005)$ \\
Number of Democratic papers & -0.0043 & 0.0402 \\
& $(0.0175)$ & $(0.0005)$ \\
\hline$R^{2}$ & 0.0182 & 0.9983 \\
Number of counties & 365 & 361 \\
Number of city-years & 2398 & 2288 \\
\hline
\end{tabular}

Notes: Unit of analysis is the city-year. Data are from presidential election years 1868-1928. All models include election-year fixed effects. Sample includes continuing newspapers only. Standard errors in parentheses are clustered by county.

Supplemental Appendix Table C.6: Effect of newspaper entry/exit on total circulation

Dependent variable: Change in $\log$ (total circulation in market)

\begin{tabular}{lccccc}
\hline Data source: & Observed & Observed & Observed & Simulated & Simulated \\
\hline Change in number of daily newspapers & 0.2359 & 0.2785 & 0.3084 & 0.3838 & 0.3717 \\
& $(0.0106)$ & $(0.0112)$ & $(0.0142)$ & $(0.0053)$ & $(0.0058)$ \\
Holds continuing paper circulation constant? & & $\mathrm{X}$ & & & \\
Allows lag effect? & & & $\mathrm{X}$ & & $\mathrm{X}$ \\
\hline$R^{2}$ & 0.1596 & 0.1800 & 0.1530 & 0.8525 & 0.8416 \\
Number of counties & 996 & 1002 & 961 & 1009 & 968 \\
Number of city-years & 9734 & 9958 & 9012 & 10079 & 9018 \\
\hline
\end{tabular}

Notes: Unit of analysis is the city-year. Data are from presidential election years 1868-1928. All models include election-year fixed effects. Sample includes city-years with at least one newspaper. Standard errors in parentheses are clustered by county. Specifications are linear regression models of change in $\log$ (total circulation) on change in number of newspapers and (where indicated) its lag. The reported coefficient is the sum of the coefficient on the change in number of newspapers and (where indicated) its lag. Where indicated we hold continuing paper circulation constant by replacing the circulation of continuing papers with its lag. 
Supplemental Appendix Table C.7: Sources for detailed readership survey data

\begin{tabular}{|c|c|c|c|c|}
\hline Survey year & City & Title & Publisher & Publication year \\
\hline 1929 & Detroit & An Analysis of the Detroit Newspaper Readers & American Association of Advertising Agencies & 1930 \\
\hline 1929 & Washington, DC & An Analysis of the Washington Newspaper Readers & American Association of Advertising Agencies & 1930 \\
\hline 1930 & Boston & An Analysis of the Boston Newspaper Readers & American Association of Advertising Agencies & 1930 \\
\hline 1930 & Buffalo, NY & Buffalo Newspaper Reader Survey & American Association of Advertising Agencies & 1932 \\
\hline 1931 & St. Louis & St. Louis Newspaper Reader Survey & American Association of Advertising Agencies & 1931 \\
\hline 1939 & Los Angeles & Los Angeles Newspaper Reader Survey & American Association of Advertising Agencies & 1939 \\
\hline 1942 & Los Angeles & The Census of Circulations: A Study of Los Angeles Newspaper Readers & Los Angeles Times & 1942 \\
\hline 1946 & Washington, DC & Washington, DC Newspaper Reader Survey & American Association of Advertising Agencies & 1946 \\
\hline 1960 & Boston & The New Boston: A Study of Adult Newspaper Reader Information & Globe Newspaper Company & 1961 \\
\hline 1961 & Philadelphia & Philadelphia Market Profile: Daily Newspapers & Bulletin Company & 1962 \\
\hline \multirow[t]{2}{*}{1962} & Boston & A Profile of the New Boston: A Study of the Adult Reading Audiences & Boston Record American & 1962 \\
\hline & & of the Three Major Weekday Newspaper Properties in the ABC Retail Trading Zone & & \\
\hline 1962 & Boston & A Profile of the New Boston: A Study of the Adult Reading Audiences & Boston Record American & 1962 \\
\hline 1963 & Los Angeles & $\begin{array}{c}\text { of the Three Major Weekday Newspaper Properties in a 24-couty New England Area } \\
\text { Profile of the Los Angeles Market: A Study of the Adult Reading Audiences } \\
\text { of Daily Newspapers in the Los Angeles Standard Metropolitan Area }\end{array}$ & Advertising Research Foundation & 1963 \\
\hline 1966 & Philadelphia & Philadelphia Market Newspaper Profile: Daily Newspapers & Bulletin Company & 1967 \\
\hline \multirow[t]{2}{*}{1967} & Chicago & Chicago Imprint: A Study of Metropolitan Chicago Readers of Daily & Tribune Company & 1967 \\
\hline & & and Sunday Newspapers, Newspaper Magazines and Selected National Magazines & & \\
\hline 1968 & Boston & Boston Today: A Study of the Market and its Newspaper Readers & Globe Newspaper Company & 1969 \\
\hline 1969 & Seattle & Seattle Area Market Study & Seattle Times & 1969 \\
\hline
\end{tabular}


Supplemental Appendix Table C.8: Overlap and affiliation

Ratio of number of overlapping readers to number predicted under independent demand model

\begin{tabular}{lccc}
\hline Data source: & Mean & SE of mean & $N$ \\
\hline & & & \\
Two Republican papers & 1.7551 & 0.3385 & 28 \\
One Republican, one Democratic & 1.4417 & 0.1132 & 31 \\
Two Democratic papers & 1.5008 & 0.2884 & 5 \\
\hline
\end{tabular}

Notes: Unit of analysis is a pair of newspapers in the same market. The sample includes all pairs with two affiliated papers in a diverse market with at least three affiliated newspapers. Independent demand model assumes that the share of readers overlapping between any two newspapers is the product of their market shares.

Supplemental Appendix Table D.1: Sensitivity of parameter estimates to omitting unobservables from model

\begin{tabular}{ccc}
\hline & Baseline & No unobservables \\
\hline Demand parameters & & \\
$\underline{\beta}$ & -0.2906 & -0.1757 \\
$\bar{\beta}$ & $(0.0676)$ & $(0.0502)$ \\
& 0.8137 & 0.6862 \\
$\Gamma_{s}$ & $(0.0759)$ & $(0.0550)$ \\
& 0.5645 & 0.5300 \\
$\Gamma_{d}$ & $(0.0669)$ & $(0.0602)$ \\
& 0.3004 & 0.3719 \\
& $(0.0469)$ & $(0.0275)$
\end{tabular}

Supply parameters

$\begin{array}{ccc}a_{l} & 7.4447 & 8.6340 \\ & (1.2626) & (1.2037) \\ \sigma_{\xi} & 0.2277 & 0.1938 \\ & (0.0298) & (0.0255)\end{array}$

Notes: Column "baseline" presents estimates of a selection of parameters from the corresponding tables in the paper. Column "no unobservables" presents estimates of the same parameters from a model in which we constrain $\sigma_{v}^{m k t}=\sigma_{v}^{\text {town }}=0$ and treat $\tau_{t}$ as nonstochastic in demand estimation. 
Supplemental Appendix Table D.2: Estimates by fraction politically independent consumers

\begin{tabular}{|c|c|c|c|c|c|}
\hline & Baseline & $\begin{array}{c}\text { Social } \\
\text { planner }\end{array}$ & $\begin{array}{l}\text { Allow joint } \\
\text { operating } \\
\text { agreements }\end{array}$ & $\begin{array}{l}\text { Allow joint } \\
\text { ownership }\end{array}$ & $\begin{array}{c}\text { Optimal } \\
\text { marginal } \\
\text { cost } \\
\text { subsidy }\end{array}$ \\
\hline & \multicolumn{5}{|c|}{ Share of households reading diverse papers } \\
\hline Full sample & 0.029 & 0.334 & 0.039 & 0.011 & 0.133 \\
\hline \multicolumn{6}{|c|}{ Fraction independent (measured using variation over time) } \\
\hline Above-median & 0.033 & 0.311 & 0.043 & 0.019 & 0.131 \\
\hline Below-median & 0.036 & 0.482 & 0.040 & 0.008 & 0.291 \\
\hline \multicolumn{6}{|c|}{ Fraction independent (measured using variation across offices) } \\
\hline Above-median & 0.043 & 0.382 & 0.046 & 0.016 & 0.224 \\
\hline \multirow[t]{2}{*}{ Below-median } & 0.031 & 0.416 & 0.038 & 0.008 & 0.191 \\
\hline & \multicolumn{5}{|c|}{ Total surplus per household } \\
\hline Full sample & 4.24 & 8.56 & 4.29 & 3.49 & 6.05 \\
\hline \multicolumn{6}{|c|}{ Fraction independent (measured using variation over time) } \\
\hline Above-median & 4.90 & 8.35 & 4.65 & 4.01 & 6.10 \\
\hline Below-median & 3.94 & 10.82 & 3.88 & 2.90 & 7.73 \\
\hline \multicolumn{6}{|c|}{ Fraction independent (measured using variation across offices) } \\
\hline Above-median & 4.82 & 9.17 & 4.45 & 3.82 & 6.65 \\
\hline Below-median & 3.89 & 9.64 & 3.91 & 3.09 & 6.64 \\
\hline
\end{tabular}

Notes: See supplemental appendix section D for details. 
Supplemental Appendix Table D.3: Demand model estimates with politically independent consumers

\begin{tabular}{|c|c|c|c|}
\hline & \multirow[t]{2}{*}{ Baseline } & \multicolumn{2}{|c|}{$\begin{array}{l}\text { Allowing for politically } \\
\text { independent consumers }\end{array}$} \\
\hline & & $\begin{array}{c}\text { Variation over } \\
\text { time }\end{array}$ & $\begin{array}{c}\text { Variation across } \\
\text { offices }\end{array}$ \\
\hline \multirow[t]{2}{*}{$\alpha$} & 0.1798 & 0.1827 & 0.1805 \\
\hline & $(0.0032)$ & $(0.0042)$ & $(0.0035)$ \\
\hline \multirow[t]{2}{*}{$\underline{\beta}$} & -0.2906 & -0.4236 & -0.3728 \\
\hline & $(0.0676)$ & $(0.0910)$ & $(0.0823)$ \\
\hline \multirow[t]{2}{*}{$\bar{\beta}$} & 0.8137 & 0.9543 & 0.8979 \\
\hline & $(0.0759)$ & $(0.1020)$ & $(0.0915)$ \\
\hline \multirow[t]{2}{*}{$\Gamma_{s}$} & 0.5645 & 0.4189 & 0.4512 \\
\hline & $(0.0669)$ & $(0.0676)$ & $(0.0648)$ \\
\hline \multirow{2}{*}{$\Gamma_{d}$} & 0.3004 & 0.2154 & 0.2538 \\
\hline & $(0.0469)$ & $(0.0720)$ & $(0.0608)$ \\
\hline \multirow[t]{2}{*}{$\sigma_{\zeta}$} & 0.7017 & 0.7003 & 0.6998 \\
\hline & $(0.0077)$ & $(0.0077)$ & $(0.0077)$ \\
\hline \multirow[t]{2}{*}{$\mu_{v}^{\text {town }}$} & 0.0466 & 0.0638 & 0.0834 \\
\hline & $(0.0422)$ & $(0.0441)$ & $(0.0466)$ \\
\hline \multirow[t]{2}{*}{$\sigma_{v}^{\text {town }}$} & 0.2783 & 0.2787 & 0.2798 \\
\hline & $(0.0135)$ & $(0.0135)$ & $(0.0135)$ \\
\hline \multirow[t]{2}{*}{$\mu_{\rho}^{0}$} & -0.0714 & -0.1057 & -0.1444 \\
\hline & $(0.0850)$ & $(0.0889)$ & $(0.0937)$ \\
\hline \multirow[t]{2}{*}{$\mu_{\rho}^{1}$} & 1.9952 & 1.9954 & 1.9951 \\
\hline & $(0.0336)$ & $(0.0336)$ & $(0.0336)$ \\
\hline
\end{tabular}

Notes: See supplemental appendix section $\mathrm{D}$ for details. 
Supplemental Appendix Table D.4: Sensitivity to unmodeled horizontal differentiation

\begin{tabular}{|c|c|c|c|c|}
\hline & \multicolumn{2}{|c|}{ Morning-evening (ME) model } & \multicolumn{2}{|c|}{ Baseline model, estimated on ME data } \\
\hline & Baseline & $\mathrm{JOA}$ & Baseline & $\mathrm{JOA}$ \\
\hline Markets with newspapers & 1064 & 1064 & 1074 & 1074 \\
\hline Markets with multiple newspapers & 301 & 465 & 279 & 466 \\
\hline Share of households reading a newspaper & 0.41 & 0.43 & 0.41 & 0.44 \\
\hline Avg. price in multi-paper markets & 5.20 & 6.60 & 5.65 & 6.79 \\
\hline Avg. ad revenue per reader in multi-paper markets & 11.46 & 12.45 & 11.01 & 12.18 \\
\hline \multicolumn{5}{|l|}{ Per household: } \\
\hline Consumer surplus & 3.68 & 3.85 & 3.59 & 3.98 \\
\hline Newspaper profit & 0.16 & 0.14 & 0.45 & 0.55 \\
\hline Advertiser profit & 0.39 & 0.00 & 0.45 & 0.00 \\
\hline Total surplus & 4.23 & 4.00 & 4.50 & 4.53 \\
\hline \multicolumn{5}{|l|}{ Diversity } \\
\hline Markets with diverse papers & 174 & 264 & 152 & 261 \\
\hline Share of households in markets with diverse papers & 0.26 & 0.34 & 0.24 & 0.34 \\
\hline Share of households reading diverse papers & 0.029 & 0.034 & 0.029 & 0.040 \\
\hline
\end{tabular}

Notes: Table shows averages over 5 simulations. The first two columns are based on the model defined in section D of the supplemental appendix. The second two columns are based on our baseline model,

estimated on data from the model simulated in the first column. A market has diverse papers if it has at least one Republican and one Democratic paper, and a household reads diverse papers if it reads at least one Republican and one Democratic paper. "Baseline" is simulation of the estimated model. "JOA" is simulation of a model in which newspapers jointly set subscription and advertising prices to maximize total newspaper profits. Average price is an annual subscription price. Average ad revenue is reported per reader per year. Surplus and profit numbers are reported in dollars per household. 
Supplemental Appendix Table D.5: Comparing simulated and actual newspaper subscription prices

\begin{tabular}{ccccc}
\hline & \multicolumn{2}{c}{ Observed mean price of } & \multicolumn{2}{c}{ Simulated mean price of } \\
\cline { 2 - 5 } & $\begin{array}{c}\text { Democratic } \\
\text { newspapers }\end{array}$ & $\begin{array}{c}\text { Republican } \\
\text { newspapers }\end{array}$ & $\begin{array}{c}\text { Democratic } \\
\text { newspapers }\end{array}$ & $\begin{array}{c}\text { Republican } \\
\text { newspapers }\end{array}$ \\
\hline 1D & 4.52 & - & 4.64 & - \\
1R & - & 4.68 & - & 4.58 \\
2D & 5.11 & - & 5.32 & - \\
1D/1R & 4.95 & 4.98 & 5.16 & 5.26 \\
2R & - & 5.09 & - & 5.17 \\
\hline
\end{tabular}

Notes: Each column reports the mean annual subscription price for newspapers of a given affiliation in a given market configuration. The first two columns are from the observed data; the second two columns are an average over 5 simulations at the parameters reported in the paper.

Supplemental Appendix Table D.6: Historical changes in variable costs

\begin{tabular}{cccccc}
\hline Year & \multirow{2}{*}{ MC } & \multicolumn{2}{c}{ Number of daily newspapers } & \multicolumn{2}{c}{ Markets with diverse papers } \\
& & Actual & Simulated & Actual & Simulated \\
\hline 1924 & 8.17 & 1338 & 1402 & 183 & 143 \\
1868 & 13.22 & 199 & 94 & 49 & 11 \\
\hline
\end{tabular}

Notes: The table compares the number of daily papers and the number of markets with diverse papers in US as predicted by our model against the historical market attributes in the US Newspaper Panel introduced in Gentzkow, Shapiro, and Sinkinson (2011). We use our baseline model to simulate the number of daily papers and the number of markets with diverse papers in 1924 . We simulate 1868 by assuming that the only change in model parameters between 1868 and 1924 is a decline in marginal cost $M C$ driven entirely by changes in paper and ink prices. To estimate the percentage difference in $M C$ between these two periods, we multiply the 1924 variable cost share of newsprint and ink, obtained from the Inland Press data, by the percentage difference in the real price of newsprint between the two periods, obtained from Gentzkow et al. (2006). Column (2) presents the estimated $M C$ as average annual variable cost per copy in dollars. 
Supplemental Appendix Table D.7: Effect of reducing maximum entrants on equilibrium and surplus-maximizing outcomes

\begin{tabular}{|c|c|c|c|c|}
\hline & \multicolumn{2}{|c|}{ Maximum number of entrants: 6} & \multicolumn{2}{|c|}{ Maximum number of entrants: 3} \\
\hline & Baseline & $\begin{array}{l}\text { Maximizing } \\
\text { total surplus }\end{array}$ & Baseline & $\begin{array}{l}\text { Maximizing } \\
\text { total surplus }\end{array}$ \\
\hline Markets with newspapers & 951 & 1910 & 949 & 1910 \\
\hline Markets with multiple newspapers & 256 & 1845 & 256 & 1843 \\
\hline Share of households reading a newspaper & 0.39 & 0.91 & 0.37 & 0.88 \\
\hline Avg. price in multi-paper markets & 5.48 & 0.05 & 5.38 & 0.00 \\
\hline Avg. ad revenue per reader in multi-paper markets & 11.24 & 11.31 & 11.44 & 11.52 \\
\hline Consumer surplus & 3.44 & 15.69 & 3.17 & 12.39 \\
\hline Firm profit & 0.41 & -17.51 & 0.51 & -14.79 \\
\hline Advertiser profit & 0.39 & 10.39 & 0.30 & 10.19 \\
\hline Total surplus & 4.24 & 8.56 & 3.98 & 7.79 \\
\hline \multicolumn{5}{|l|}{ Diversity } \\
\hline Markets with diverse papers & 143 & 1370 & 133 & 1332 \\
\hline Share of households in market. with diverse papers & 0.22 & 0.84 & 0.21 & 0.79 \\
\hline Share of households reading diverse papers & 0.029 & 0.334 & 0.022 & 0.243 \\
\hline
\end{tabular}

Notes: Table shows averages over 5 simulations at the parameters reported in the paper. Columns (1) and (2)

have $J^{\max }=6$ and are identical to columns (1) and (3) in the corresponding table of the paper. Columns (3) and (4) have $J^{\max }=3$. The distribution of profits between firms and advertisers is indeterminate in columns (2) and (4); we assume that advertisers capture all surplus from advertising. A market has diverse papers if it has at least one Republican and one Democratic paper, and a household reads diverse papers if it reads at least one Republican and one Democratic paper. "Baseline" is simulation of the estimated model. In columns (2) and (4), the social planner chooses the number of papers in each market, affiliations, ad prices, and circulation prices to maximize total surplus, with the constraint that all prices must be weakly positive. Average price is an annual subscription price. Average ad revenue is reported per reader per year. Surplus and profit numbers are reported in dollars per household. 
Supplemental Appendix Table D.8: Fixed-cost subsidies to newspapers

\begin{tabular}{lcc}
\hline & Baseline & $\begin{array}{c}\text { Optimal } \\
\text { fixed-cost } \\
\text { subsidy }\end{array}$ \\
\hline Amount of subsidy & & $\begin{array}{c}\$ 12639 \text { per } \\
\text { paper }\end{array}$ \\
Markets with newspapers & 951 & 951 \\
Markets with multiple newspapers & 256 & 717 \\
Share of households reading a newspaper & 0.39 & 0.49 \\
Avg. price in multi-paper markets & 5.48 & 5.58 \\
Avg. ad revenue per reader in multi-paper markets & 11.24 & 11.03 \\
Per household: & & \\
Consumer surplus & 3.44 & 5.13 \\
Newspaper profit & 0.41 & 0.25 \\
Advertiser profit & 0.39 & 0.93 \\
Cost of subsidy & 0.00 & 1.56 \\
Total surplus & 4.24 & 4.75 \\
\hline Diversity & & \\
Markets with diverse papers & & 421 \\
Share of households in markets with diverse papers & 0.22 & 0.45 \\
Share of households reading diverse papers & 0.029 & 0.071 \\
\hline
\end{tabular}

Notes: Table shows averages over 5 counterfactual simulations at the parameters reported in tables 7 and 8 of the paper. A market has diverse papers if it has at least one Republican and one Democratic paper, and a household reads diverse papers if it reads at least one Republican and one Democratic paper. "Baseline" is simulation of the estimated model. Subsidies are chosen to maximize total surplus. "Optimal fixed-cost subsidy" provides a fixed per-household payment to the second and all following entrants. Average price is an annual subscription price. Average ad revenue is reported per reader per year. Surplus and profit numbers, as well as cost of subsidy, are reported in annual dollars per household. Cost of subsidy includes a 30 percent cost of public funds. 
Supplemental Appendix Table D.9: Alternative specifications

\begin{tabular}{|c|c|c|c|c|c|}
\hline & & \multicolumn{2}{|c|}{ Households reading diverse papers } & \multicolumn{2}{|c|}{ Total surplus } \\
\hline & & $\begin{array}{l}\text { Allow joint } \\
\text { ownership }\end{array}$ & $\begin{array}{c}\text { Optimal MC } \\
\text { subsidy }\end{array}$ & $\begin{array}{l}\text { Allow joint } \\
\text { ownership }\end{array}$ & $\begin{array}{c}\text { Optimal MC } \\
\text { subsidy }\end{array}$ \\
\hline \multirow[t]{3}{*}{ (1) } & Preferred estimate & 0.011 & 0.133 & 3.49 & 6.05 \\
\hline & (Standard Errors) & $(0.001)$ & $(0.014)$ & $(0.092)$ & $(0.162)$ \\
\hline & [Simulation Error] & {$[0.001]$} & {$[0.001]$} & {$[0.049]$} & {$[0.059]$} \\
\hline \multicolumn{6}{|c|}{ Changing Calibrated Values } \\
\hline (2) & Increase marginal cost by $25 \%$ & 0.012 & 0.171 & 2.81 & 4.54 \\
\hline (3) & Decrease marginal cost by $25 \%$ & 0.009 & 0.119 & 4.06 & 7.53 \\
\hline (4) & Increase $a_{h}$ by $25 \%$ & 0.007 & 0.133 & 4.18 & 8.91 \\
\hline (5) & Decrease $a_{h}$ by $25 \%$ & 0.013 & 0.222 & 2.34 & 3.42 \\
\hline (6) & Increase average readership overlap by $25 \%$ & 0.019 & 0.141 & 3.90 & 6.14 \\
\hline (7) & Decrease average readership overlap by $25 \%$ & 0.006 & 0.116 & 3.26 & 5.93 \\
\hline (8) & Increase spatial correlation of unobservables by $25 \%$ & 0.010 & 0.139 & 3.46 & 6.11 \\
\hline (9) & Decrease spatial correlation of unobservables by $25 \%$ & 0.011 & 0.131 & 3.51 & 6.02 \\
\hline \multicolumn{6}{|c|}{ Modifying Model Specification } \\
\hline$(10)$ & Endogenous $J_{t}$ in demand model & 0.011 & 0.130 & 3.51 & 6.02 \\
\hline (11) & Add flexibility to fixed cost distribution & 0.007 & 0.126 & 3.29 & 5.76 \\
\hline (12) & Add flexibility to affiliation choice in demand model & 0.010 & 0.137 & 3.46 & 6.12 \\
\hline (13) & Add distance to HQ as utility shifter in demand model & 0.009 & 0.161 & 3.34 & 6.40 \\
\hline (14) & Add HQ circulation as utility shifter in demand model & 0.009 & 0.144 & 3.41 & 6.26 \\
\hline$(15)$ & Incorporate hinterland towns in market ideology & 0.003 & 0.185 & 3.20 & 7.22 \\
\hline$(16)$ & Fix all prices to mean price & 0.008 & 0.176 & 3.26 & 6.64 \\
\hline (17) & Add price as utility shifter in demand model & 0.016 & 0.102 & 3.95 & 5.61 \\
\hline \multicolumn{6}{|c|}{ Modifying Estimation Sample } \\
\hline (18) & Tighten population cut-offs for markets & 0.008 & 0.142 & 3.35 & 6.06 \\
\hline (19) & Remove markets with independent papers & 0.011 & 0.124 & 3.48 & 5.87 \\
\hline$(20)$ & Remove markets with unaffiliated papers & 0.010 & 0.125 & 3.41 & 5.90 \\
\hline$(21)$ & Remove markets near major cities & 0.012 & 0.099 & 3.99 & 5.89 \\
\hline$(22)$ & Remove towns with missing data for nearby newspapers & 0.011 & 0.142 & 3.46 & 6.08 \\
\hline$(23)$ & Remove market pairs with cross-market co-ownership & 0.011 & 0.131 & 3.44 & 5.95 \\
\hline$(24)$ & Remove towns in the top $10 \%$ by population & 0.011 & 0.137 & 3.47 & 6.09 \\
\hline$(25)$ & Remove towns in the bottom $10 \%$ by population & 0.011 & 0.135 & 3.49 & 6.05 \\
\hline$(26)$ & Remove towns and markets in the South & 0.008 & 0.285 & 2.93 & 7.50 \\
\hline
\end{tabular}

Notes: See the robustness appendix of the paper for details. 
Supplemental Appendix Figure A.1: Fit of entry decisions in supply model
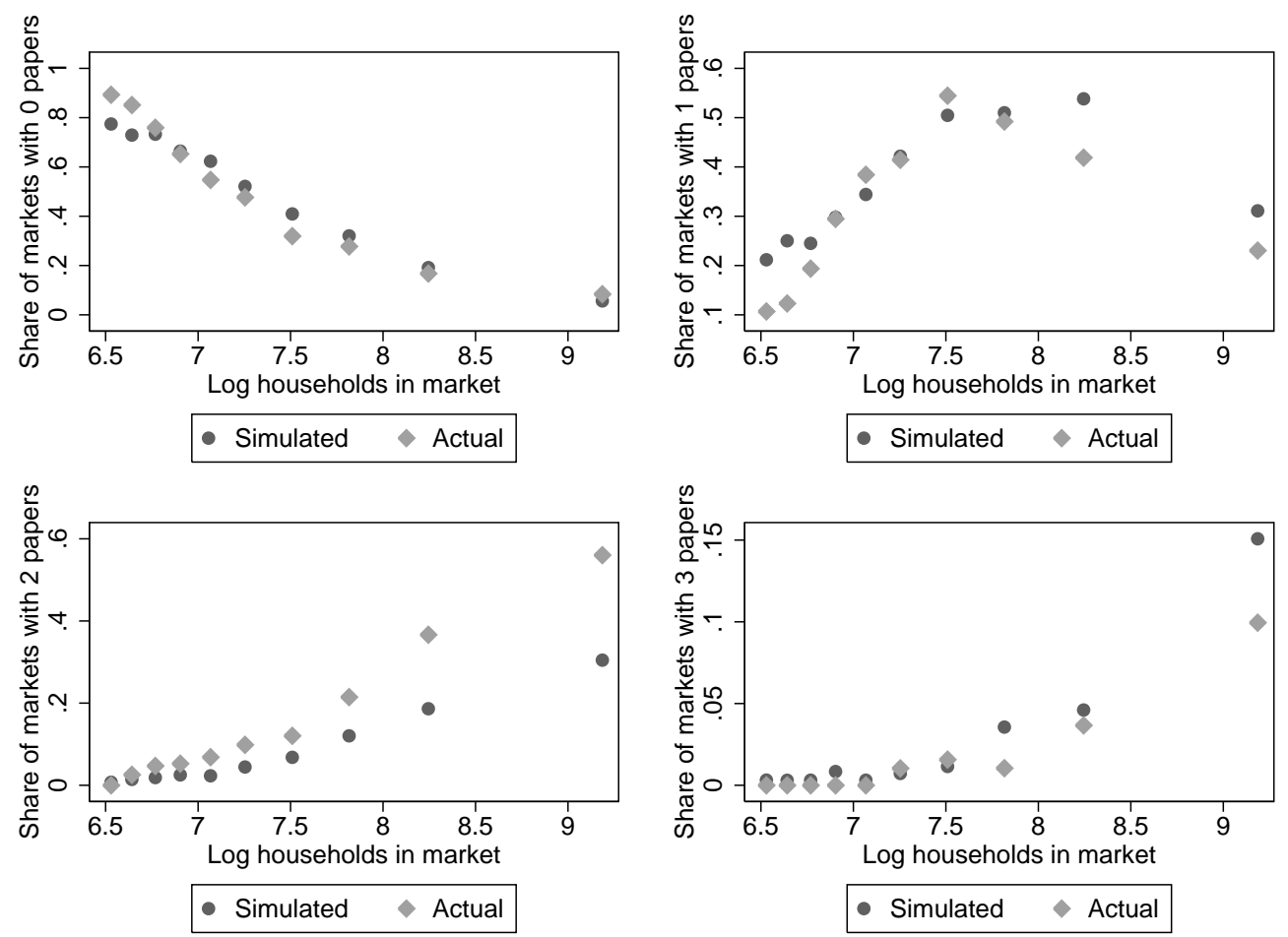

Notes: The panels of the figure show the share of markets with zero, one, two, and three papers respectively by market size in the actual data and data simulated from our baseline model. Simulated shares are the average across five simulations. Markets are divided into deciles by number of households. Markets with four, five, or six papers are omitted from the figure, but included in the denominator in computing shares. 
Supplemental Appendix Figure C.1: Demand for partisanship

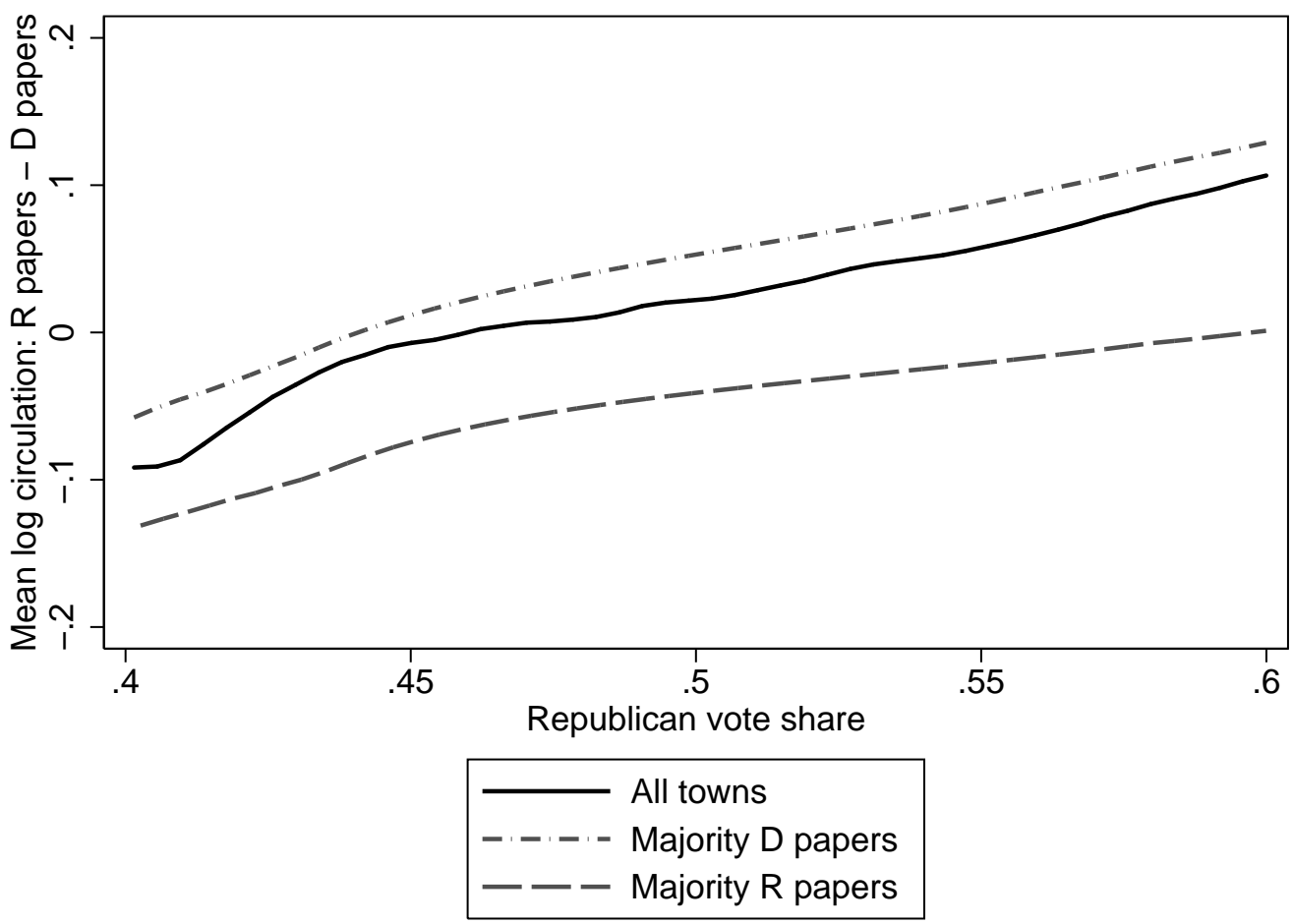

Notes: Data are from the cross-section of news-reading towns in 1924 defined in section 2.3. Republican vote share is the average Republican share of the two-party vote in presidential elections from 1868-1928. The sample includes all towns with at least one Democratic newspaper and at least one Republican newspaper in which the Republican vote share is between 0.4 and 0.6. "Majority R papers" refers to the set of towns in which there are more Republican than Democratic newspapers available. "Majority D papers" refers to the set of towns in which there are more Democratic than Republican newspapers available. The plot is a local polynomial plot of degree 0, using the Epanechnikov kernel with a bandwidth of .03 for the full sample and .07 for the majority R / majority D samples. 
Supplemental Appendix Figure D.1: Market structure and changes in variable costs
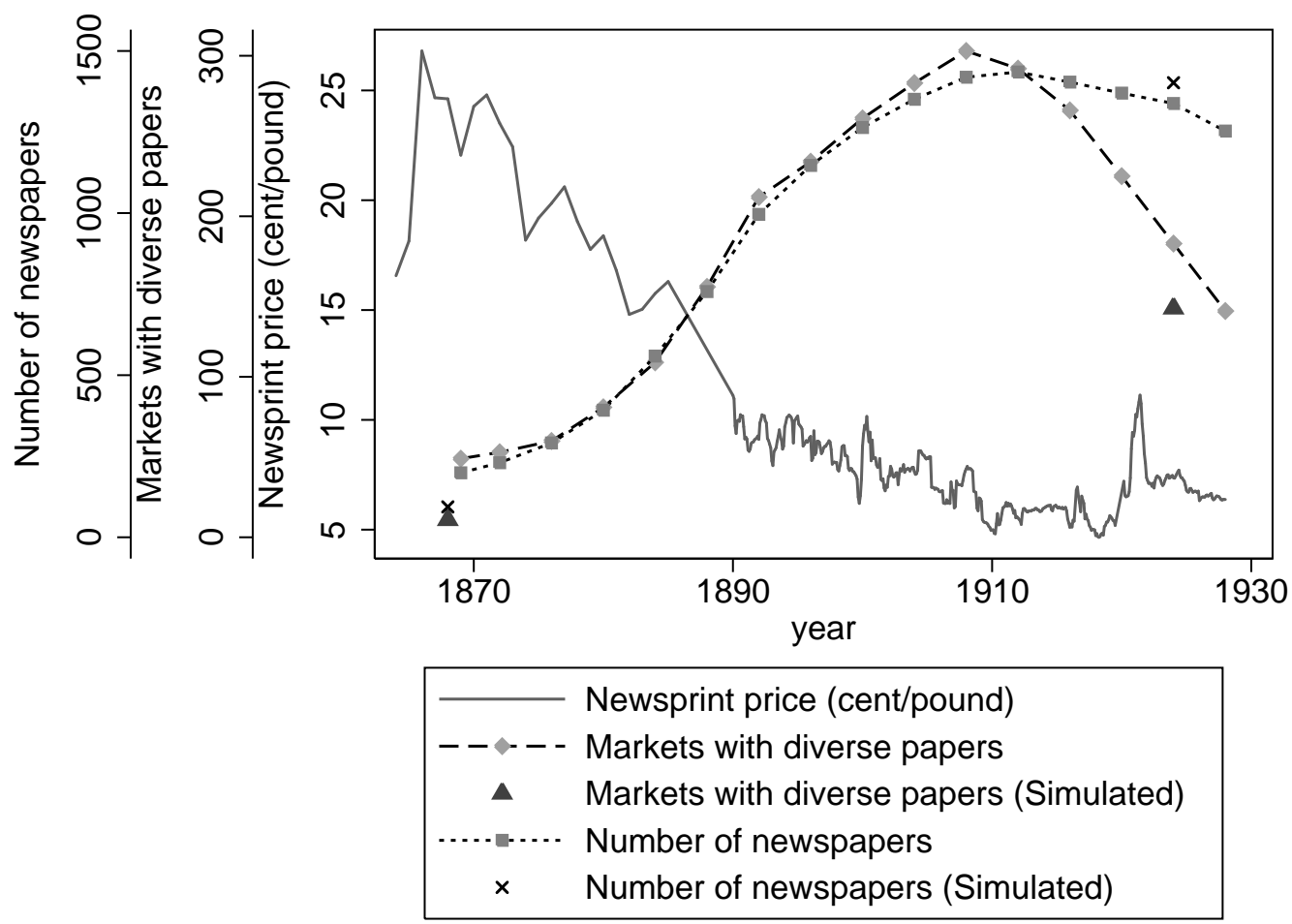

Notes: The figure compares the number of daily papers and the number of markets with diverse papers in US as predicted by our model against the historical market attributes in the US Newspaper Panel introduced in Gentzkow et al. (2011). We use our baseline model to simulate the number of daily papers and the number of markets with diverse papers in 1924. We simulate 1868 by assuming that the only change in model parameters between 1868 and 1924 is a decline in marginal cost $M C$ driven entirely by changes in paper and ink prices. To estimate the percentage difference in $M C$ between these two periods, we multiply the 1924 variable cost share of newsprint and ink, obtained from the Inland Press data, by the percentage difference in the real price of newsprint between the two periods, obtained from Gentzkow et al. (2006). 
Supplemental Appendix Figure D.2: Number of diverse markets: Baseline vs. social planner

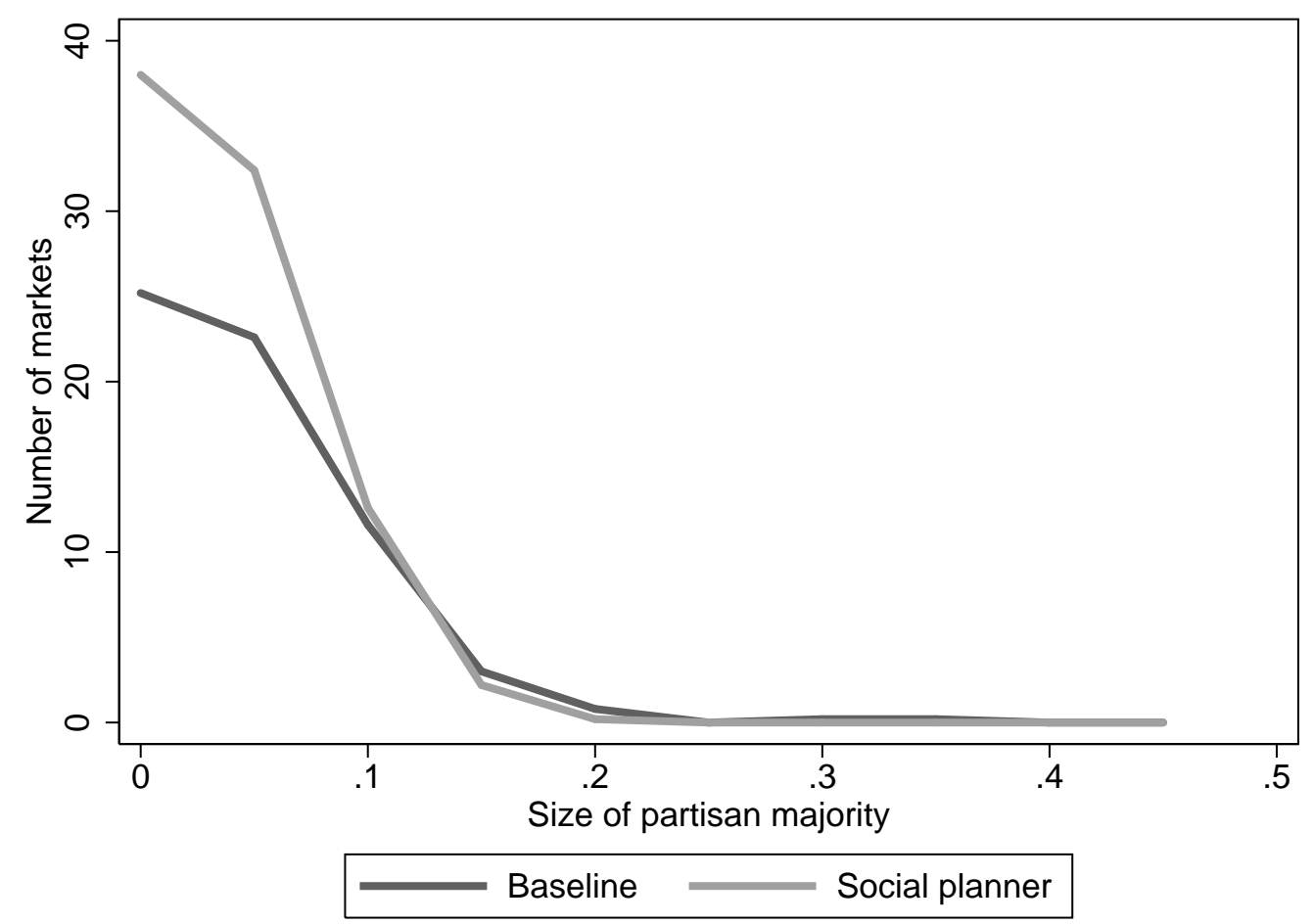

Notes: The plot shows the number of two-paper markets that are diverse as a function of the size of the partisan majority of consumers, defined as the absolute value of the difference between the Republican share of the two-party vote and 0.5. Data are in bins of width 0.05 . The line labeled "Baseline" shows the mean across five simulations from our baseline model. The line labeled "Social planner" shows the mean across five simulations from the counterfactual in which a social planner chooses all post-entry endogenous variables. 